\title{
Magainin as an Antiviral Peptide of SARS-CoV-2 Main Protease for Potential Inhibitor: An In Silico Approach
}

\author{
TAUFIK MUHAMMAD FAKIH*, MENTARI LUTHFIKA DEWI, EKY SYAHRONI \\ Department of Pharmacy, Faculty of Mathematics and Natural Sciences, Universitas Islam Bandung \\ Jl. Tamansari No. 1 Kota Bandung, West Java, Indonesia. 40116 \\ *Email: taufikmuhammadf@gmail.com
}

Received 01 May 2020; Received in revised form 01 June 2020;

Accepted 17 June 2020; Available online 30 June 2020

\begin{abstract}
The new coronavirus (SARS-CoV-2), which caused the global pandemic Coronavirus Disease-2019 (COVID-2019), has infected nearly 206 countries. There is still little information about molecular compounds that can inhibit the development of infections caused by this disease. It is crucial to discover competent natural inhibitor candidates, such as antiviral peptides, because they have a variety of biological activities and have evolved to target biochemical machinery from different pathogens or host cell structures. In silico studies will be carried out, including protein-peptide docking and protein-protein docking, to identify, evaluate, and explore the affinity and molecular interactions of the Magainin-1 and Magainin-2 peptide molecules derived from frog skin (Xenopus laevis) to the main protease macromolecule (Mpro) SARS-CoV-2, and its effect on the ACE-2 receptor (Angiotensin Converting Enzyme-2 Receptor). Proteinpeptide docking simulations show that both peptide molecules have a good affinity for the active site area of the SARS-CoV-2 Mpro macromolecule. These results were then confirmed using protein-protein docking simulations to observe the ability of the peptide molecule in preventing attachment to the ACE-2 receptor surface area. In silico studies show that Magainin-2 has the best affinity, with a bond free energy value of $-3054.53 \mathrm{~kJ} / \mathrm{mol}$. Then the protein-protein docking simulation provided by Magainin-2 prevented the attachment of ACE-2 receptors, with an ACE score of $1697.99 \mathrm{~kJ} / \mathrm{mol}$. Thus, through in silico research, the Magainin peptide molecule can be further investigated in the development of new antiviral peptides for the treatment of infectious diseases of COVID-19.
\end{abstract}

Keywords: antiviral peptide; COVID-19; in silico; Magainin; SARS-CoV-2

\section{INTRODUCTION}

The emergence of symptoms such as fever, cough, fatigue, sputum production, shortness of breath, sore throat, headache along with several reports of diarrhea and vomiting began to increase as a cause of pneumonia cases since December 2019 and later identified as a new coronavirus in Wuhan, Hubei Province, China (Guan et al., 2020; Wang et al., 2020). On January 12, 2020, the WHO first named the 2019-novel coronavirus (2019-nCoV) and officially referred to this disease as the coronavirus 2019 (COVID-19) and as a global emergency disease as a result of concern globally. The International Committee of Coronavirus Study Group (CSG) recommends using the name as SARS-CoV-2, published on February 11, 2020 (Guo et al., 2020).

Two overlapping polyproteins function to encode the SARS-CoV-2 genome consisting of $\sim 30,000$ nucleotides, namely pp1a and pp1ab. Both polyproteins are needed by coronavirus for replication and transcription ( $\mathrm{Lu}$ et al., 2020). Through this polyprotein, a functional polypeptide is released through a proteolytic process involving the main protease (Mpro) of SARS-CoV-2 (Ge et al., 2013). Previous studies have shown that the functional structure between SARS-CoV-2 and SARS-CoV is identical based on the genome's complete phylogenetic analysis (Chen et al., 2009; Letko et al., 2020). By analyzing the order and analysis of the evolution of this coronavirus, it is suspected that bats act as coronavirus's natural hosts. The coronavirus may have been transferred to humans as an intermediate host by binding to the ACE-2 receptor (Angiotensin Converting Enzyme-2 Receptor) (Zhou et al., 2020).

ACE-2 receptors act as functional receptors because they can mediate coronaviruses' entry (SARS-CoV or SARSCoV-2) into host cells. SARS-CoV-2 involves the ACE-2 receptor's surface with an affinity 
comparable to SARS-CoV (Kirchdoerfer et al., 2018; Walls et al., 2019). A strong bond at the ACE-2 receptor can explain part of the efficient transmission of SARS-CoV-2 in humans, as occurs in SARS-CoV (Park et al., 2016). Therefore, the inhibition of the attachment of SARS-CoV-2 to the ACE-2 receptor is a pathway in developing natural inhibitors for infectious diseases of COVID-19.

Some literature describes frog skin's antiviral activity (Xenopus laevis) because it is considered an abundant source of antiviral peptides. These peptides are produced in skin glands, are deployed in stressful events, and present cationic $\alpha$-helical secondary structures, with 10-50 amino acids (Marcocci et al., 2018; Shartouny \& Jacob, 2019). Magainin-1 and Magainin-2 are examples of antiviral peptides with 23 amino acid residues and show efficient inhibition of viruses (Matanic \& Castilla, 2004). Previously, several variants of Magainin also presented lysine-rich regions or many lysine residues in their structures, showing the best results in inhibiting viruses. Previous research has suggested that cationic loading associated with amphipathic structures can allow these peptides to interact with anionic phospholipids in viral envelopes, consequently disrupting their structure by several unknown mechanisms and exerting virucidal activity (Dean et al., 2010).

Through this research, the mechanism of action of the antiviral peptides Magainin-1 and Magainin-2 will be proven against SARS-CoV2 Mpro and their effect on inhibiting the binding of ACE-2 receptors' binding using in silico. This in silico study can be utilized to identify, evaluate, and characterize potential components of SARS-COV-2 (Kumar et al., 2020). In particular, SARS-CoV-2 Mpro has been considered a target because it is a major part of forming coronavirus characteristics. Thus, the results of this research are expected to obtain the structure of a reference antiviral peptide in developing a candidate drug for COVID-19 infection.

\section{MATERIALS AND METHODS}

SARS-CoV-2 Mpro Macromolecule

Preparation. The macromolecules used are the main proteases (Mpro) of the novel coronavirus 2019 (2019-nCoV or SARS-CoV-2) downloaded from Protein Data Bank (http://www.rcsb.org/pdb) with PDB ID 6LU7 (Jin et al., 2020). SARS-CoV-2 Mpro macromolecules were prepared by removing water molecules and natural inhibitors, adding polar hydrogen atoms, and calculating the Kollman charge.

Antiviral Peptide Molecule Preparation. The test molecule used was the sequencing of the antiviral peptide Magainin-1 and Magainin2 derived from the frog skin (Xenopus laevis), which had been modeled using PEPFOLD 3.5 (http://bioserv.rpbs.univ-paris-diderot.fr/PEPFOLD/) (Figure 1). PEP-FOLD 3.5 is a server that is used to model peptide sequencing into three-dimensional conformation using the de novo method with amino acids between 5 and 50 (Maupetit et al., 2009; Thévenet et al., 2012; Chavan \& Deobagkar, 2015; Lamiable et al., 2016). This method can obtain a peptide sequence without the protein database that overcomes the limitations of the methods that rely on peptide mass fingerprinting (PMF) databases. This can be used for non-sequenced organisms, antibodies, posttranslational modification (PTM), and endogenous peptides (Bellows \& Floudas, 2010). The results of the peptide molecular modelling will be used as input for protein-peptide docking simulations. 


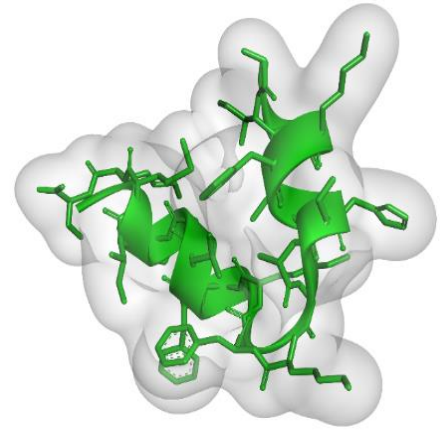

a

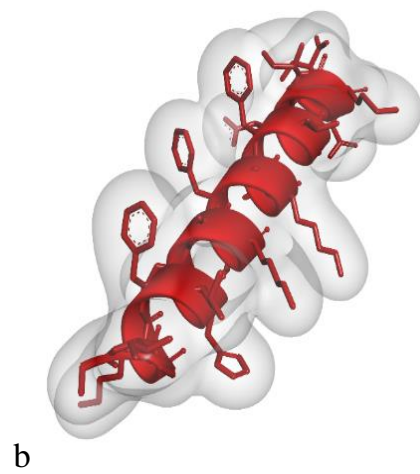

Figure 1. The molecular structure of antiviral peptides: a. Magainin-1 (GIGKFLHSAGKFGKAFVGEIMKS); b. Magainin-2 (GIGKFLHSAKKFGKAFVGEIMNS)

\section{Peptide-Binding Sites in SARS-CoV-2} Mpro Identification. Identification, evaluation, and exploration of the binding site area most responsible for the antiviral activity of the SARS-CoV-2 Mpro macromolecule were prepared using BIOVIA Discovery Studio 2016 (BIOVIA, 2016). All amino acid residues found around natural inhibitors within a defined radius (between 2 to $4 \AA$ ) are prepared for the binding site between the surface of protein macromolecules and peptide molecules in protein-peptide docking simulations.

Protein-Peptide Docking Simulations. PatchDock is used for protein-peptide docking simulations (Kaczor et al., 2013; Sathya \& Rajeswari, 2016; Aruleba et al., 2018). All antiviral peptide molecules for these simulations are modeled, and polar hydrogen atoms are added using the de novo method. Protein-peptide complex types are selected by default RMSD 4.0 $\AA$ grouping. The representation of the Connolly point's surface from the molecule into different components, including convex, concave, and flat patch, is generated through the PatchDock algorithm. PatchDock is optimized, refined, overhauled, and re-selected the side chain interface from the top 10 candidate solutions. It also changes relative molecular orientation by limiting flexibility in the side chains of interacting surfaces and allowing the movement of small, rigid objects. Analysis of the results of proteinpeptide docking simulations was carried out using BIOVIA Discovery Studio 2016 (BIOVIA, 2016).

ACE-2 Receptor Macromolecule Preparation. The ACE-2 receptor
(Angiotensin Converting Enzyme-2 Receptor) macromolecules were downloaded from the Protein Data Bank (http://www.rcsb.org/pdb) with PDB ID 2AJF (Li et al., 2005). This ACE2 receptor macromolecule is prepared by removing water molecules and natural inhibitors, adding polar hydrogen atoms, and calculating the Kollman charge.

Protein-Protein Docking Simulations. PatchDock is used to simulate protein docking of both peptide-protein complexes resulting from the protein-peptide docking methods (Kaczor et al., 2013; Sathya \& Rajeswari, 2016; Aruleba et al., 2018). The default RMSD $4.0 \AA$ grouping is used, and the protein-protein complex type is selected. The representation of the Connolly dot surface of the molecule into different components such as convex, concave, and flat patch is generated through the PatchDock algorithm. PatchDock is optimized, refined, overhauled, and reselected the side chain interface from the top 10 candidate solutions. It also changes the orientation of the molecule relative by limiting flexibility in the side chains of the interacting surface and allowing the movement of small, rigid objects. The system's suitability is verified by visualization observations using BIOVIA Discovery Studio 2016 (BIOVIA, 2016).

\section{RESULT AND DISCUSSION}

Protein-Peptide Docking Simulations. All antiviral peptides derived from frog skin (Xenopus laevis) have been proven to have affinity and interaction with the main protease (Mpro) of SARS-CoV-2, which acts as a target macromolecule using the protein-peptide 
docking methods. The docking simulation results in Table 1 show that Magainin-2 has the best affinity with the active site SARS-CoV-2 Mpro compared to Magainin-1 and natural inhibitors, with binding free energy values of $-3054.53 \mathrm{~kJ} / \mathrm{mol},-201.46 \mathrm{~kJ} / \mathrm{mol}$, and $-1171.44 \mathrm{~kJ} / \mathrm{mol}$, respectively. This phenomenon shows a promising sign that
Magainin-2 has strong and stable bonds and interactions in the active site area of the SARSCoV-2 Mpro macromolecule. After that, all the complex results of protein-peptide docking simulations were selected for further studies using protein-protein docking simulations against ACE-2 receptors (Angiotensin Converting Enzyme-2 Receptor).

Table 1. Binding free energy between the peptide molecule and the SARS-CoV-2 Mpro macromolecule

\begin{tabular}{cc}
\hline Peptide Molecule & Binding Free Energy (kJ/mol) \\
\hline Natural inhibitor & $-1171.44 \mathrm{~kJ} / \mathrm{mol}$ \\
\hline Magainin-1 & $-201.46 \mathrm{~kJ} / \mathrm{mol}$ \\
\hline Magainin-2 & $-3054.53 \mathrm{~kJ} / \mathrm{mol}$ \\
\hline
\end{tabular}

The peptide molecules Magainin-1 and Magainin-2 show binding positions adjacent to natural inhibitors, and these three molecules can interact in polar patches of SARS-CoV-2 Mpro macromolecules (Figure 2). However, natural inhibitors and the Magainin-1 peptide molecule can only interact with some amino acid residues found in the active sites of the SARS-CoV-2 Mpro macromolecules. Natural inhibitors can only form 5 interactions, consisting of 3 hydrogen bonds (with Met49, Asn142, and Gln189) and 2 hydrophobic interactions (with His41 and Met 165). Then the Magainin-1 peptide molecule can only form 6 interactions, which include 5 hydrogen bonds (with Arg4, Lys5, Lys137, Ser139, and Phe140) and 1 electrostatic interaction (with Ser284).

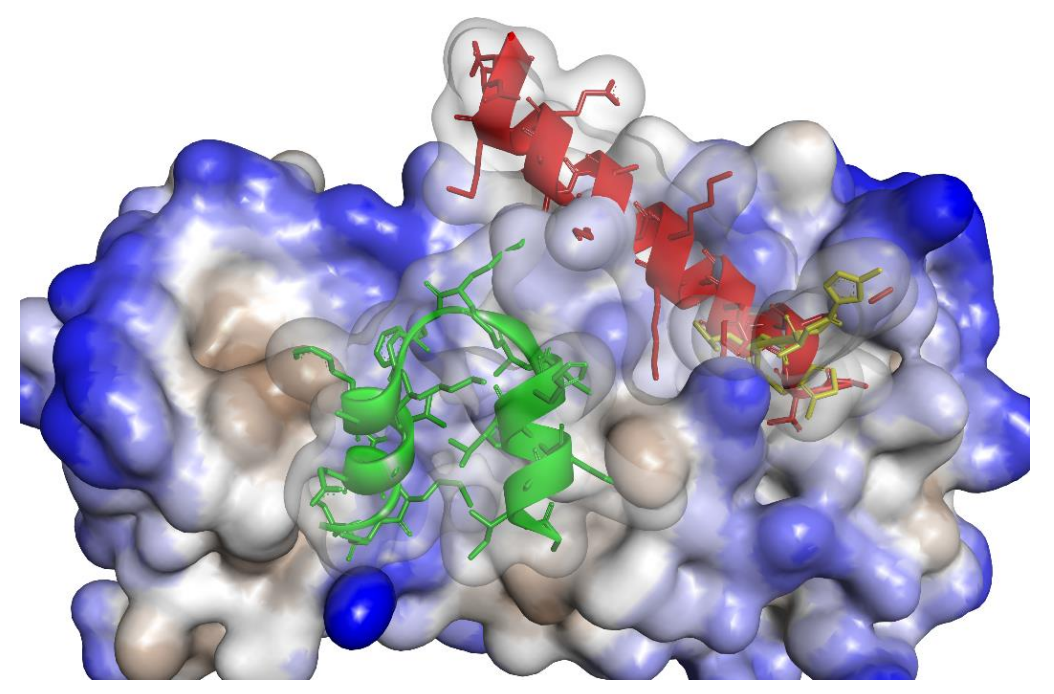

Figure 2. The conformation of natural inhibitor (yellow), Magainin-1 (green), and Magainin-2 (red) molecules in the SARS-CoV-2 Mpro macromolecular binding site

Interestingly, the Magainin-2 peptide molecule has more interaction with the active site area of the Mpro SARS-CoV-2 macromolecule than the natural inhibitor and Magainin-1 peptide molecule. These peptide molecules are capable of forming 13 interactions, including 6 hydrogen bonds (with Thr24, Thr25, His41, Met49, Cys145, and Gln192), 1 electrostatic interaction (with
Glu166), and 6 hydrophobic interactions (with Met165, Leu167, Pro168, Ala191, Ala193, and Ala194) (Table 2). Also, the binding position between the Magainin-2 peptide molecule and natural inhibitors has similarities. This phenomenon is proven by forming bonds with several amino acid residues such as His41, Met49, and Met165. 
Table 2. Profiles of amino acid residues from SARS-CoV-2 Mpro macromolecules that interact with peptide molecules

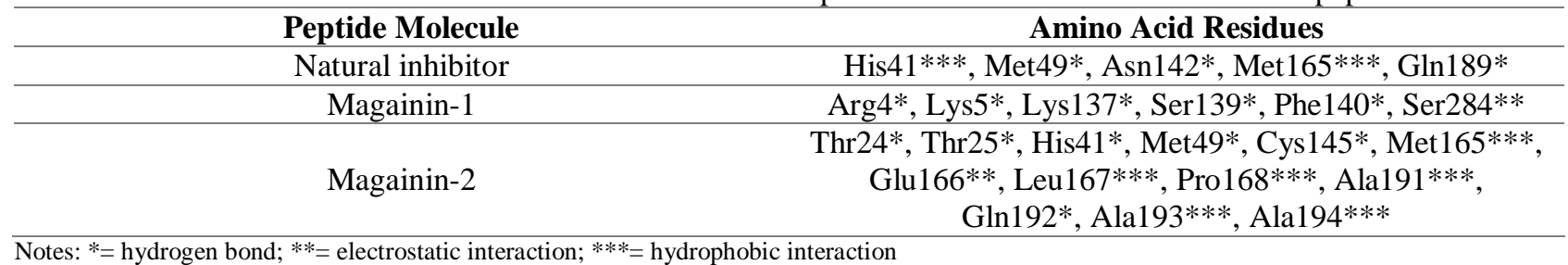

These interactions can be formed due to hydrogen bonds, especially peptide molecules, which act as hydrogen bond donors and protein amino acid residues as hydrogen bond acceptors. Most hydrogen bonds between protein macromolecules and peptide molecules are relatively strong, with average bond lengths ranging from $3 \AA$. In addition to hydrogen bonds, interactions between peptide molecules and SARS-CoV-2 Mpro are also dominated by hydrophobic interactions. So it can be predicted that hydrogen bonds and hydrophobic interactions that contribute to protein macromolecules are responsible for stabilizing protein-peptide complexes.

Protein-Protein Docking Simulations. Furthermore, identification, evaluation, and exploration using the protein-protein docking methods after the protein macromolecule complex and peptide molecules are formed in the previous stage. The purpose of this docking simulations is to observe the effect of each protein-peptide complex in preventing the attachment of SARS-CoV-2 Mpro macromolecules to the surface area of the ACE2 receptor. Best affinity with strong and stable interaction of peptide molecules against SARSCoV-2 Mpro macromolecules is predicted to inhibit the entry of coronavirus into cells and host tissues due to the inability of coronavirus to reach ACE-2 receptors in the signaling process of viral infection. It is also important to explore amino acid residues that play an important role in resisting the formation of molecular interactions between the SARSCoV-2 Mpro macromolecular binding site and the surface of the ACE-2 receptor.

Table 3. The atomic contact energy (ACE) score of each protein-peptide complex against the ACE-2 receptor

\begin{tabular}{cc}
\hline Protein-Peptide Complex & Atomic Contact Energy (kJ/mol) \\
\hline Natural inhibitor + SARS-CoV-2 Mpro & $-204.26 \mathrm{~kJ} / \mathrm{mol}$ \\
\hline Magainin-1 + SARS-CoV-2 Mpro & $231.75 \mathrm{~kJ} / \mathrm{mol}$ \\
\hline Magainin-2 + SARS-CoV-2 Mpro & $1697.99 \mathrm{~kJ} / \mathrm{mol}$ \\
\hline
\end{tabular}

Protein-protein docking simulations results in Table 3 show that the Magainin-1 and Magainin-2 protein-peptide complex have positive ACE scores, with values of 231.75 $\mathrm{kJ} / \mathrm{mol}$ and $1697.99 \mathrm{~kJ} / \mathrm{mol}$, respectively. In contrast, natural inhibitors have a negative ACE score, with a value of $-204.26 \mathrm{~kJ} / \mathrm{mol}$. This phenomenon proves that the ability of the two Magainin peptide molecules to inhibit the attachment of ACE-2 receptors is better than natural inhibitors.

Table 4. Amino acid residues from ACE-2 receptor that play a role in the formation of unfavorable interactions

\begin{tabular}{cc}
\hline Protein-Peptide Complex & Amino Acid Residues \\
\hline Natural inhibitor + SARS-CoV-2 Mpro & Arg115, Lys131, Cys133, Gln139 \\
\hline Magainin-1 + SARS-CoV-2 Mpro & Gly319, Ala387, Arg559 \\
\hline Magainin-2 + SARS-CoV-2 Mpro & Lys313, Val316, Ser317, Ala387, Pro426, Asp427, \\
& Asn546, Thr548, Gln552, Phe555, Asn556 \\
\hline
\end{tabular}

Moreover, the molecular structure of Magainin-2 is capable of forming many unfavorable interactions on the surface of the ACE-2 receptor. Several amino acid residues that form unfavorable interactions include Lys313, Val316, Ser317, Ala387, Pro426, Asp427, Asn546, Thr548, Gln552, Phe555, and Asn556 (Table 4). This interaction is predicted 
to be responsible for preventing the formation of infection signals in SARS-COV-2 (Cheng et al., 2016; Wheeler et al., 2016).

\section{CONCLUSION}

Peptide molecules Magainin-1 and Magainin-2 can bind strongly and stably to the binding site area of the SARS-CoV-2 Mpro macromolecule. Interestingly, Magainin-2 has the best affinity and interaction with the SARSCoV-2 Mpro macromolecule's active site, with a binding free energy value of $-3054.53 \mathrm{~kJ} / \mathrm{mol}$. The Magainin-2 peptide molecule can also inhibit the formation of interactions with the ACE-2 receptor surface because it has a positive ACE score, with a value of 1697.99 $\mathrm{kJ} / \mathrm{mol}$. Therefore, the results of this research indicate that the peptide molecules Magainin-1 and Magainin-2 have the potential to be further developed as natural candidate inhibitors of the SARS-CoV-2 Mpro macromolecules in the treatment of infectious diseases of COVID-19.

\section{ACKNOWLEDGMENT}

The authors thank the LPPM (Institute for Research and Community Service), Universitas Islam Bandung, for the research financially supported by the Special Research Grant Program 2020, No.039/B.04/LPPM/IV/2020.

\section{REFERENCES}

Aruleba RT, Adekiya TA, Oyinloye BE, Kappo AP. 2018. Structural studies of predicted ligand binding sites and molecular docking analysis of Slc2a4 as a therapeutic target for the treatment of cancer. International Journal of Molecular Sciences. vol 19(2): 1-15. doi: https://doi.org/10.3390/ijms19020386.

Bellows ML, Floudas CA. 2010. Computational methods for de novo protein design and its applications to the human immunodeficiency virus 1, purine nucleoside phosphorylase, ubiquitin specific protease 7, and histone demethylases. Current Drug Targets. vol 11(3): 264-278. doi: https://doi.org/10.2174/138945010790711914.

BIOVIA DS. 2016. Discovery Studio Modeling Environment, Release 2018, San Diego: Dassault Systèmes.

Chavan SG, Deobagkar DD. 2015. An in silico insight into novel therapeutic interaction of LTNF peptideLT10 and design of structure based peptidomimetics for putative anti-diabetic activity. PLoS ONE. vol 10(3): 1-20. doi: https://doi.org/10.1371/journal.pone.0121860.
Chen Y, Cai H, Pan J, Xiang N, Tien P, Ahola T, Guo D. 2009. Functional screen reveals SARS coronavirus nonstructural protein nsp14 as a novel cap N7 methyltransferase. Proceedings of the National Academy of Sciences of the United States of America. vol 106(9): 3484-3489. doi: https://doi.org/10.1073/pnas.0808790106.

Cheng X, Guinn EJ, Buechel E, Wong R, Sengupta R, Shkel IA, Record Jr. MT. 2016. Basis of protein stabilization by $\mathrm{K}$ Glutamate: Unfavorable interactions with carbon, oxygen groups. Biophysical Journal. vol 111(9): 1854-1865. doi: https://doi.org/10.1016/j.bpj.2016.08.050.

Dean RE, O'Brien LM, Thwaite JE, Fox MA, Atkins H, Ulaeto DO. 2010. A carpet-based mechanism for direct antimicrobial peptide activity against vaccinia virus membranes. Peptides. vol 31(11): 1966-1972.

doi: https://doi.org/10.1016/j.peptides.2010.07.028.

Ge XY, Li JL, Yang XL, Chmura AA, Zhu G, Epstein JH, Mazet JK, Hu B, Zhang W, Peng C, Zhang YJ, Luo CM, Tan B, Wang N, Zhu Y, Crameri G, Zhang SY, Wang LF, Daszak P, Shi ZL. 2013. Isolation and characterization of a bat SARS-like coronavirus that uses the ACE2 receptor. Nature. vol 503: 535-538. doi: https://doi.org/10.1038/nature12711. Guan WJ, Ni ZY, Hu Y, Liang WH, Ou CQ, He JX, Liu L, Shan H, Lei CL, Hui DSC, Du B, Li LJ, Zeng G, Yuen KY, Chen RC, Tang CL, Wang T, Chen PY, Xiang J, Li S, Wang JL, Liang ZJ, Peng YX, Wei L, Liu Y, Hu YH, Peng P, Wang JM, Liu JY, Chen Z, Li G, Zheng ZJ, Qiu SQ, Luo J, Ye CJ, Zhu SY, Zhong NS. 2020. Clinical characteristics of coronavirus disease 2019 in China. The New England Journal of Medicine. vol 382: 1708-1720. doi: https://doi.org/10.1056/NEJMoa2002032.

Guo YR, Cao QD, Hong ZS, Tan YY, Chen SD, Jin HJ, Tan KS, Wang DY, Yan Y. 2020. The origin, transmission and clinical therapies on coronavirus disease 2019 (COVID-19) outbreak - An update on the status. Military Medical Research. vol 7(11): 110. https://doi.org/10.1186/s40779-020-00240-0.

Jin Z, Du X, Xu Y, Deng Y, Liu M, Zhao Y, Zhang B, Li X, Zhang L, Peng C, Duan Y, Yu J, Wang L, Yang K, Liu F, Jiang R, Yang X, You T, Liu X, Yang X, Bai F, Liu H, Liu X, Guddat LW, Xu W, Xiao G, Qin C, Shi Z, Jiang H, Rao Z, Yang H. 2020. Structure of Mpro from COVID-19 virus and discovery of its inhibitors. Nature. vol 582: 289-293. doi: https://doi.org/10.1038/s41586-0202223-y.

Kaczor AA, Selent J, Sanz F, Pastor M. 2013. Modeling complexes of transmembrane proteins: Systematic analysis of protein-protein docking tools. Molecular Informatics. vol 32(8): 717-733. doi: https://doi.org/10.1002/minf.201200150.

Kirchdoerfer RN, Wang N, Pallesen J, Wrapp D, Turner HL, Cottrell CA, Corbett KS, Graham BS, McLellan JS, Ward AB. 2018. Stabilized coronavirus spikes are resistant to conformational 
changes induced by receptor recognition or proteolysis. Scientific Reports. vol 8: 1-11. doi: https://doi.org/10.1038/s41598-018-34171-7.

Kumar S, Maurya VK, Prasad AK, Bhatt MLB, Saxena SK. 2020. Structural, glycosylation and antigenic variation between 2019 novel coronavirus (2019$\mathrm{nCoV}$ ) and SARS coronavirus (SARS-CoV). VirusDisease. vol 31(1): 13-21. doi: https://doi.org/10.1007/s13337-020-00571-5.

Lamiable A, Thévenet P, Rey J, Vavrusa M, Derreumaux P, Tufféry P. 2016. PEP-FOLD3: faster de novo structure prediction for linear peptides in solution and in complex. Nucleic Acids Research. vol 44(1): 449-454. doi: https://doi.org/10.1093/nar/gkw329.

Letko M, Marzi A, Munster V. 2020. Functional assessment of cell entry and receptor usage for SARS-CoV-2 and other lineage B betacoronaviruses. Nature Microbiology. vol 5(4): 1-8. doi: https://doi.org/10.1038/s41564-0200688-y.

Li F, Li W, Farzan M, Harrison SC. 2005. Structural biology: Structure of SARS coronavirus spike receptor-binding domain complexed with receptor. Science. vol 309(5742): 1864-1868. doi: https://doi.org/10.1126/science.1116480.

Lu R, Zhao X, Li J, Niu P, Yang B, Wu H, Wang W, Song H, Huang B, Zhu N, Bi Y, Ma X, Zhan F, Wang L, Hu T, Zhou H, Hu Z, Zhou W, Zhao L, Chen J, Meng Y, Wang J, Lin Y, Yuan J, Xie Z, Ma J, Liu WJ, Wang D, Xu W, Holmes EC, Gao GF, Wu G, Chen W, Shi W, Tan W. 2020. Genomic characterisation and epidemiology of 2019 novel coronavirus: implications for virus origins and receptor binding. The Lancet. vol 395(10224): 565-574. doi: https://doi.org/10.1016/S01406736(20)30251-8.

Marcocci ME, Amatore D, Villa S, Casciaro B, Aimola P, Franci G, Grieco P, Galdiero M, Palamara AT, Mangoni ML, Nencioni L. 2018. The amphibian antimicrobial peptide temporin $b$ inhibits in vitro herpes simplex virus 1 infection. Antimicrobial Agents and Chemotherapy. vol 62(5): 1-13. doi: https://doi.org/10.1128/AAC.02367-17.

Matanic VCA, Castilla V. 2004. Antiviral activity of antimicrobial cationic peptides against Junin virus and herpes simplex virus. International Journal of Antimicrobial Agents. vol 23(4): 382-389. doi: https://doi.org/10.1016/j.ijantimicag.2003.07.022.

Maupetit J, Derreumaux P, Tuffery P. 2009. PEP-FOLD: An online resource for de novo peptide structure prediction. Nucleic Acids Research. vol 37: 498-503. doi: https://doi.org/10.1093/nar/gkp323.

Park JE, Li K, Barlan A, Fehr AR, Perlman S, McCray
PB, Gallagher T. 2016. Proteolytic processing of middle east respiratory syndrome coronavirus spikes expands virus tropism. Proceedings of the National Academy of Sciences of the United States of America. vol 113(43): 12262-12267. doi: https://doi.org/10.1073/pnas.1608147113.

Sathya D, Rajeswari VD. 2016. In Silico docking analysis of bioactive compounds from Chinese medicine Jinqi Jiangtang Tablet (JQJTT) using Patch Dock. Journal of Chemical and Pharmaceutical Research. vol 5(8): 15-21.

Shartouny JR, Jacob J. 2019. Mining the tree of life: Host defense peptides as antiviral therapeutics. Seminars in Cell and Developmental Biology. vol 88: $147-155$.

doi: https://doi.org/10.1016/j.semcdb.2018.03.001.

Thévenet P, Shen Y, Maupetit J, Guyon F, Derreumaux P, Tufféry P. 2012. PEP-FOLD: An updated de novo structure prediction server for both linear and disulfide bonded cyclic peptides. Nucleic Acids Research. vol 40: 288-293. doi: https://doi.org/10.1093/nar/gks419.

Walls AC, Xiong X, Park YJ, Tortorici MA, Snijder J, Quispe J, Cameroni E, Gopal R, Dai M, Lanzavecchia A, Zambon M, Rey FA, Corti D, Veesler D. 2019. Unexpected receptor functional mimicry elucidates activation of coronavirus fusion. Cell. vol 176(5): 1026-1039. doi: https://doi.org/10.1016/j.cell.2018.12.028.

Wang D, Hu B, Hu C, Zhu F, Liu X, Zhang J, Wang B, Xiang H, Cheng Z, Xiong Y, Zhao Y, Li Y, Wang X, Peng Z. 2020. Clinical characteristics of 138 hospitalized patients with 2019 novel coronavirusinfected pneumonia in Wuhan, China. JAMA Journal of the American Medical Association. vol 323(11): 1061-1069. doi: https://doi.org/10.1001/jama.2020.1585.

Wheeler SE, Seguin TJ, Guan Y, Doney AC. 2016. Noncovalent interactions in organocatalysis and the prospect of computational catalyst design. Accounts of Chemical Research. vol 49(5): 1061-1069. doi: https://doi.org/10.1021/acs.accounts.6b00096.

Zhou P, Yang XL, Wang XG, Hu B, Zhang L, Zhang W, Si HR, Zhu Y, Li B, Huang CL, Chen HD, Chen J, Luo Y, Guo H, Jiang RD, Liu MQ, Chen Y, Shen XR, Wang X, Zheng XS, Zhao K, Chen QJ, Deng F, Liu LL, Yan B, Zhan FX, Wang YY, Xiao GF, Shi ZL. 2020. A pneumonia outbreak associated with a new coronavirus of probable bat origin. Nature. $\quad$ vol 579: 270-273. doi: https://doi.org/10.1038/s41586-020-2012-7. 